\begin{tabular}{|c|c|c|c|}
\hline \multirow{3}{*}{$\begin{array}{r}\text { Case Reports in } \\
\text { Gastroenterology }\end{array}$} & \multirow{2}{*}{\multicolumn{2}{|c|}{ Case Rep Gastroenterol 2015;9:81-87 }} & \multirow[b]{3}{*}{$\begin{array}{l}\text { Karger } \\
\text { Open'access }\end{array}$} \\
\hline & & & \\
\hline & $\begin{array}{l}\text { DOI: 10.1159/000381140 } \\
\text { Publisned online: April I, } 2015\end{array}$ & $\begin{array}{l}\text { ( } 2015 \text { S. Karger AG, Basel } \\
1662-0631 / 15 / 0091-0081 \$ 39.50 / 0 \\
\text { www.karger.com/crg }\end{array}$ & \\
\hline & $\begin{array}{l}\text { This is an Open Access articl } \\
\text { Attribution-NonCommercial } 3.0 \\
\text { license), applicable to the online } \\
\text { commercial purposes only. }\end{array}$ & $\begin{array}{l}\text { the terms of the Creative Common } \\
\text { (CC BY-NC) (www.karger.com/OA } \\
\text { cle only. Distribution permitted for non }\end{array}$ & \\
\hline
\end{tabular}

\title{
Diffuse Liver Metastasis of Small-Cell Lung Cancer Presenting as Acute Liver Failure and Diagnosed by Transjugular Liver Biopsy: A Rare Case in Whom Nodular Lesions Were Detected by Enhanced CT Examination
}
S. Mishima ${ }^{a} \quad$ Y. Nozaki ${ }^{\mathrm{a}}$
S. Mikami ${ }^{\mathrm{a}}$
E. Kihira ${ }^{a}$
M. Iikurab
R. Koketsu ${ }^{\text {b }}$
H. Sugiyama ${ }^{b}$ T. Masuda ${ }^{c}$
H. Kaname ${ }^{c} \quad$ Y. Egami ${ }^{c}$
T. Nakayama ${ }^{c}$
K. Hasuoc
H. Nakamurad
T. Igari ${ }^{d}$
K. Watanabe ${ }^{a}$
N. Nagata ${ }^{a}$
T. Sakurai ${ }^{\mathrm{a}}$
C. Yokoi ${ }^{a}$
M. Kobayakawa ${ }^{a}$
Y. Kojima ${ }^{a}$
J. Akiyama ${ }^{\mathrm{a}}$
M. Imamura ${ }^{a}$
N. Masaki $i^{a}$
M. Yanase ${ }^{a}$

Departments of ${ }^{a}$ Gastroenterology, ${ }^{b}$ Respiratory Medicine, ${ }^{c}$ Radiology and ${ }^{d}$ Pathology, National Center for Global Health and Medicine, Tokyo, Japan

\section{Key Words}

Diffuse liver metastasis · Acute liver failure · Small-cell lung cancer

\section{Abstract}

Small-cell lung cancer (SCLC) is a subgroup of lung cancer with a high frequency of liver metastasis, which is a predictor of poor prognosis. Diffuse liver metastases of SCLC with no visible nodular lesions in the liver when examined using computed tomography (CT) are relatively rare; however, a few cases with rapid progression to acute liver failure that were diagnosed after death have been reported. In this paper, we report a 63-year-old man with diffuse liver metastases of SCLC that were histologically diagnosed using a transjugular liver biopsy while the patient was alive, even though no lesions were visible during a contrastenhanced CT examination. 
Mishima et al.: Diffuse Liver Metastasis of Small-Cell Lung Cancer Presenting as Acute Liver Failure and Diagnosed by Transjugular Liver Biopsy

\section{Introduction}

The liver is one of the most frequent targets of metastasis from primary malignant tumors. Most metastatic liver tumors are diagnosed using imaging techniques such as contrast-enhanced computed tomography (CT); these imaging techniques are often performed to evaluate the stage of malignancy. However, diffuse-type liver metastasis tumors without nodular lesions are considerably rare, even when contrast-enhanced CT examinations are performed; thus, an accurate diagnosis is difficult to obtain prior to death, and some cases may develop acute liver failure or, occasionally, disseminated intravascular coagulation, making a percutaneous liver biopsy difficult to perform. Therefore, most cases are diagnosed histologically as diffuse liver metastasis on a post-mortem basis. Small-cell lung cancer (SCLC) comprises approximately 15\% of all lung cancers [1] and is a subgroup of primary lung cancer that is known for its aggressive and rapid growth and early metastasis. SCLC is associated with a poor prognosis and limited treatment options, particularly in cases with liver metastasis [2]. We present the first report of a rare case in whom diffuse liver metastasis of SCLC was diagnosed histologically using a transjugular liver biopsy while the patient was alive, despite the absence of any visible lesions when examined using contrast-enhanced CT. Unfortunately the condition of this patient rapidly progressed to acute liver failure before the indications for chemotherapy could be met.

\section{Case Report}

A 63-year-old male was referred to our hospital for further care because of a considerable body weight loss (10 kg over a 1-year period), bloody phlegm for a few months and jaundice for a few days. He had visited another hospital because of hypertension and had never exhibited liver dysfunction during a routine health check-up. He had a past medical history of diabetes mellitus and tonsillitis. He also had a history of heavy smoking and alcohol consumption. While his vital signs upon examination were within the normal range (blood pressure $131 / 70 \mathrm{~mm} \mathrm{Hg}$, pulse rate $86 / \mathrm{bpm}$, body temperature $36.3^{\circ} \mathrm{C}$ ), his physical examination showed significant jaundice and hepatomegaly. His laboratory data revealed elevation of serum liver enzyme levels (aspartate aminotransferase $102 \mathrm{IU} / \mathrm{l}$, alanine aminotransferase $88 \mathrm{IU} / \mathrm{l}$, lactate dehydrogenase $650 \mathrm{IU} / \mathrm{l}$, alkaline phosphatase $723 \mathrm{IU} / \mathrm{l}$, $\gamma$-glutamyltransferase $835 \mathrm{IU} / \mathrm{l}$ ) and jaundice (total bilirubin $9.8 \mathrm{mg} / \mathrm{dl}$, direct bilirubin $7.9 \mathrm{mg} / \mathrm{dl}$ ). His serum albumin level and platelet counts were decreased (albumin $2.5 \mathrm{~g} / \mathrm{dl}$, platelets $\left.4.2 \times 10^{4} / \mu \mathrm{l}\right)$. The prothrombin time was slightly prolonged $(74.7 \%)$. As for tumor markers, the ProGRP level was prominently increased to $24,000 \mathrm{pg} / \mathrm{ml}$. Contrast-enhanced CT scans revealed a right lung tumor with a size of $15 \mathrm{~mm}$ and multiple lymph node metastases, pleural dissemination and a suspected left adrenal metastasis (fig. 1). The liver findings only showed hepatomegaly without any intrahepatic nodular lesions when using contrast-enhanced CT (fig. 2a); diffuse minimal high-echoic nodular shadows were visible during ultrasound examination (fig. 2b). Based on a transbronchial needle aspiration of a mediastinal lymph node, he was diagnosed as having stage IV SCLC (fig. 3a). Further examination to evaluate the cause of the liver dysfunction was needed before determining the chemotherapy options, and a transjugular liver biopsy was performed. A percutaneous transhepatic approach was not feasible because of a bleeding tendency. Histologically, the patient was diagnosed as having diffuse metastatic SCLC in the liver, with positive immunohistological findings for chromogranin A, synaptophysin, CD56, TTF-1 and AE1/AE3 and with a Ki-67 index of $80 \%$ (fig. $3 \mathrm{~b}$ ). Thereafter, the patient's general condition and liver failure worsened 
Mishima et al.: Diffuse Liver Metastasis of Small-Cell Lung Cancer Presenting as Acute Liver Failure and Diagnosed by Transjugular Liver Biopsy

quite rapidly, and best supportive care was selected. He died 13 days after hospital admission.

\section{Discussion}

SCLC accounts for approximately $15-18 \%$ of all lung cancers; it is the leading cause of cancer death in men worldwide and is strongly associated with smoking. The poor survival rate of SCLC is related to its invasive tendency and its high rate of metastasis, and the identification of liver metastasis has been shown to be a significant indicator of a poor prognosis [2]. Liver metastasis is diagnosed in about $50 \%$ of patients with extensive-stage SCLC [3]; however, diffuse parenchymal metastasis correlated with liver failure is an unusual and extremely rare pattern of liver metastasis. CT examinations are generally preferred for the staging of malignancy. However, in cases with diffuse malignant infiltration of the hepatic sinusoids, plain CT imaging can fail to detect gross hepatic nodules [4], while contrastenhanced CT can reveal diffuse multiple low-density, hypovascular areas in the liver [5]; in these cases, magnetic resonance imaging or FDG-PET may be useful for staging purposes [6]. Furthermore, almost all cases reported as having diffuse liver metastasis of SCLC exhibit rapid progression to acute liver failure and death. Therefore, diffuse liver metastasis is mostly diagnosed after death. As for the underlying mechanism of the progression of hepatic metastasis of SCLC to acute liver failure, massive diffuse sinusoidal infiltration and obstructive invasion of the hepatic vessels by tumor cells as well as replacement of normal liver parenchyma with malignant cells have been reported to result in hepatocyte ischemia and necrosis [5].

Seventeen well-described cases of diffuse liver metastases of SCLC causing acute liver failure have been previously reported [4-14], and these cases differ from cases of liver predominant/primary small-cell carcinoma [15]. None of these 17 cases had been histologically diagnosed prior to death, despite the absence of any visible nodular lesions in the liver observed using contrast-enhanced CT. Since coagulation abnormalities usually prohibit liver biopsy, in case of a high risk of bleeding, alternative biopsy techniques such as transjugular liver biopsy should be favored [11]. Thus, as far as we know, the case reported here is the first case of diffuse liver metastasis of SCLC diagnosed histologically based on a transjugular liver biopsy while the patient was alive, with no nodular lesions visible in the liver even using a contrast-enhanced CT scan of the abdomen. However, in our case, appropriate chemotherapy could not be performed because of the severe liver dysfunction at the time of diagnosis.

In conclusion, we report a case of diffuse liver metastasis of SCLC diagnosed histologically based on a transjugular liver biopsy that progressed rapidly to acute liver failure. A liver biopsy may be indicated early during the clinical course of SCLC patients with liver dysfunction and hepatomegaly.

\section{Acknowledgments}

The skillful technical assistance of Nami Michiaki is gratefully acknowledged. This study was supported in part by a grant for National Center for Global Health and Medicine (26A-107) to Y. Nozaki. 
Mishima et al.: Diffuse Liver Metastasis of Small-Cell Lung Cancer Presenting as Acute Liver Failure and Diagnosed by Transjugular Liver Biopsy

\section{Disclosure Statement}

None of the authors has any conflict of interest to declare concerning the material presented in this paper.

\section{References}

1 Govindan R, Page N, Morgensztern D, Read W, Tierney R, Vlahiotis A, Spitznagel EL, Piccirillo J: Changing epidemiology of small-cell lung cancer in the United States over the last 30 years: analysis of the surveillance, epidemiologic, and end results database. J Clin Oncol 2006;24:4539-4544.

$2 \mathrm{Wu}$ C, Li F, Jiao SC: Prognostic factors for survival of patients with extensive stage small cell lung cancer a retrospective single institution analysis. Asian Pac J Cancer Prev 2012;13:4959-4962.

-3 Elliott JA, Osterlind K, Hirsch FR, Hansen HH: Metastatic patterns in small-cell lung cancer: correlation of autopsy findings with clinical parameters in 537 patients. J Clin Oncol 1987;5:246-254.

4 Ihara N, Yashiro N, Kinoshita T, Yoshigi J, Ouchi T, Narita M, Hattori C, Kaneko N: Diffuse intrasinusoidal liver metastasis of small cell lung cancer causing fulminant hepatic failure: CT findings - a case report. Radiat Med 2001;19:275-277.

5 Sato K, Takeyama Y, Tanaka T, Fukui Y, Gonda H, Suzuki R: Fulminant hepatic failure and hepatomegaly caused by diffuse liver metastases from small cell lung carcinoma: 2 autopsy cases. Respir Investig 2013;51: 98-102.

6 Athanasakis E, Mouloudi E, Prinianakis G, Kostaki M, Tzardi M, Georgopoulos D: Metastatic liver disease and fulminant hepatic failure: presentation of a case and review of the literature. Eur J Gastroenterol Hepatol 2003;15:1235-1240.

7 Krause EA, Ludwig PW, Sumner HW: Metastatic carcinoma presenting as fulminant hepatic failure. Am J Gastroenterol 1979;72:651-654.

8 Harrison HB, Middleton HM 3rd, Crosby JH, Dasher MN Jr: Fulminant hepatic failure: an unusual presentation of metastatic liver disease. Gastroenterology 1981;80:820-825.

$\$ 9$ McGuire BM, Cherwitz DL, Rabe KM, Ho SB: Small-cell carcinoma of the lung manifesting as acute hepatic failure. Mayo Clin Proc 1997;72:133-139.

10 Kaira K, Takise A, Watanabe R, Mori M: Fulminant hepatic failure resulting from small-cell lung cancer and dramatic response of chemotherapy. World J Gastroenterol 2006;12:2466-2468.

11 Alexopoulou A, Koskinas J, Deutsch M, Delladetsima J, Kountouras D, Dourakis SP: Acute liver failure as the initial manifestation of hepatic infiltration by a solid tumor: report of 5 cases and review of the literature. Tumori 2006;92:354-357.

$\$ 12$ Gilbert J, Rutledge H, Koch A: Diffuse malignant infiltration of the liver manifesting as a case of acute liver failure. Nat Clin Pract Gastroenterol Hepatol 2008;5:405-408.

-13 Miyaaki H, Ichikawa T, Taura N, Yamashima M, Arai H, Obata Y, Furusu A, Hayashi H, Kohno S, Nakao K: Diffuse liver metastasis of small cell lung cancer causing marked hepatomegaly and fulminant hepatic failure. Intern Med 2010;49:1383-1386.

14 Vaideeswar P, Munot S, Rojekar A, Deodhar K: Hepatic diffuse intra-sinusoidal metastases of pulmonary small-cell carcinoma. J Postgrad Med 2012;58:230-231.

15 Lo AA, Lo EC, Li H, Zhang W, Liao J, Rao MS, Miller F, Yang GY: Unique morphologic and clinical features of liver predominant/primary small cell carcinoma - autopsy and biopsy case series. Ann Diagn Pathol 2014;18:151-156.

S. Mishima and Y. Nozaki equally contributed to this work. 


\begin{tabular}{rl|l} 
Case Reports in & \multicolumn{2}{l}{} \\
\cline { 2 - 3 } Gastroenterology & Case Rep Gastroenterol 2015;9:81-87 & $\begin{array}{l}\text { ○ 2015 S. Karger AG, Basel } \\
\text { www.karger.com/crg }\end{array}$ \\
\cline { 2 - 3 } & DOI: 10.1159/000381140 &
\end{tabular}

Mishima et al.: Diffuse Liver Metastasis of Small-Cell Lung Cancer Presenting as Acute Liver Failure and Diagnosed by Transjugular Liver Biopsy

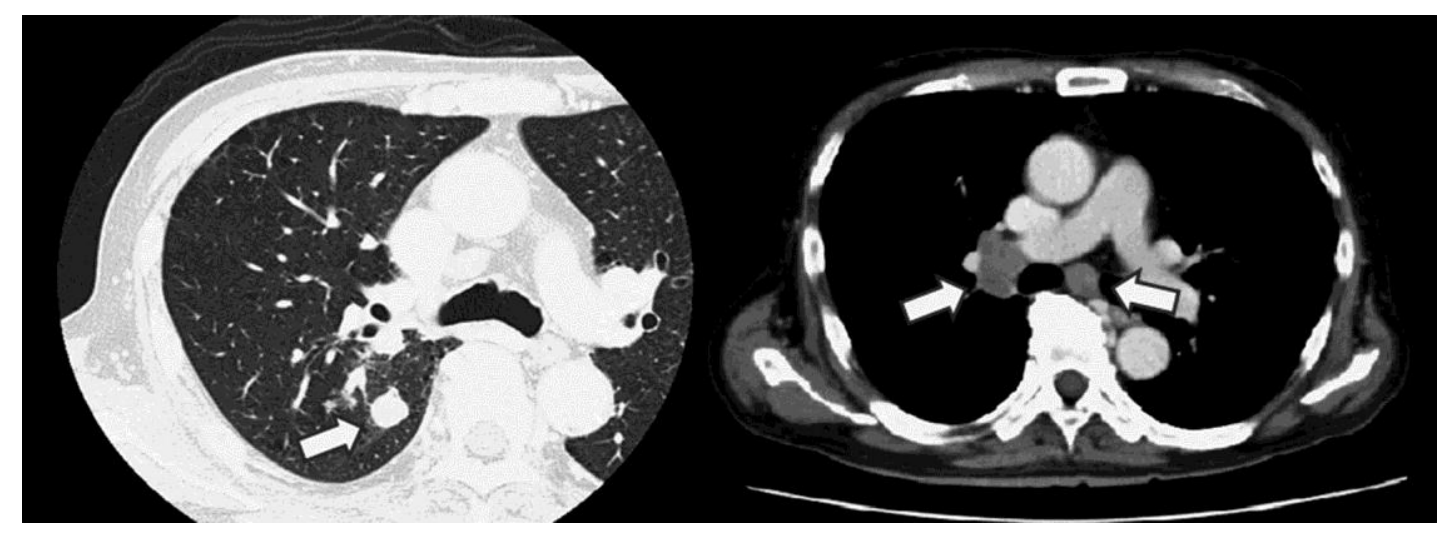

Fig. 1. Contrast-enhanced CT scans revealed a right lung tumor with a size of $15 \mathrm{~mm}$ and multiple lymph node metastases (arrows). 
Mishima et al.: Diffuse Liver Metastasis of Small-Cell Lung Cancer Presenting as Acute Liver Failure and Diagnosed by Transjugular Liver Biopsy
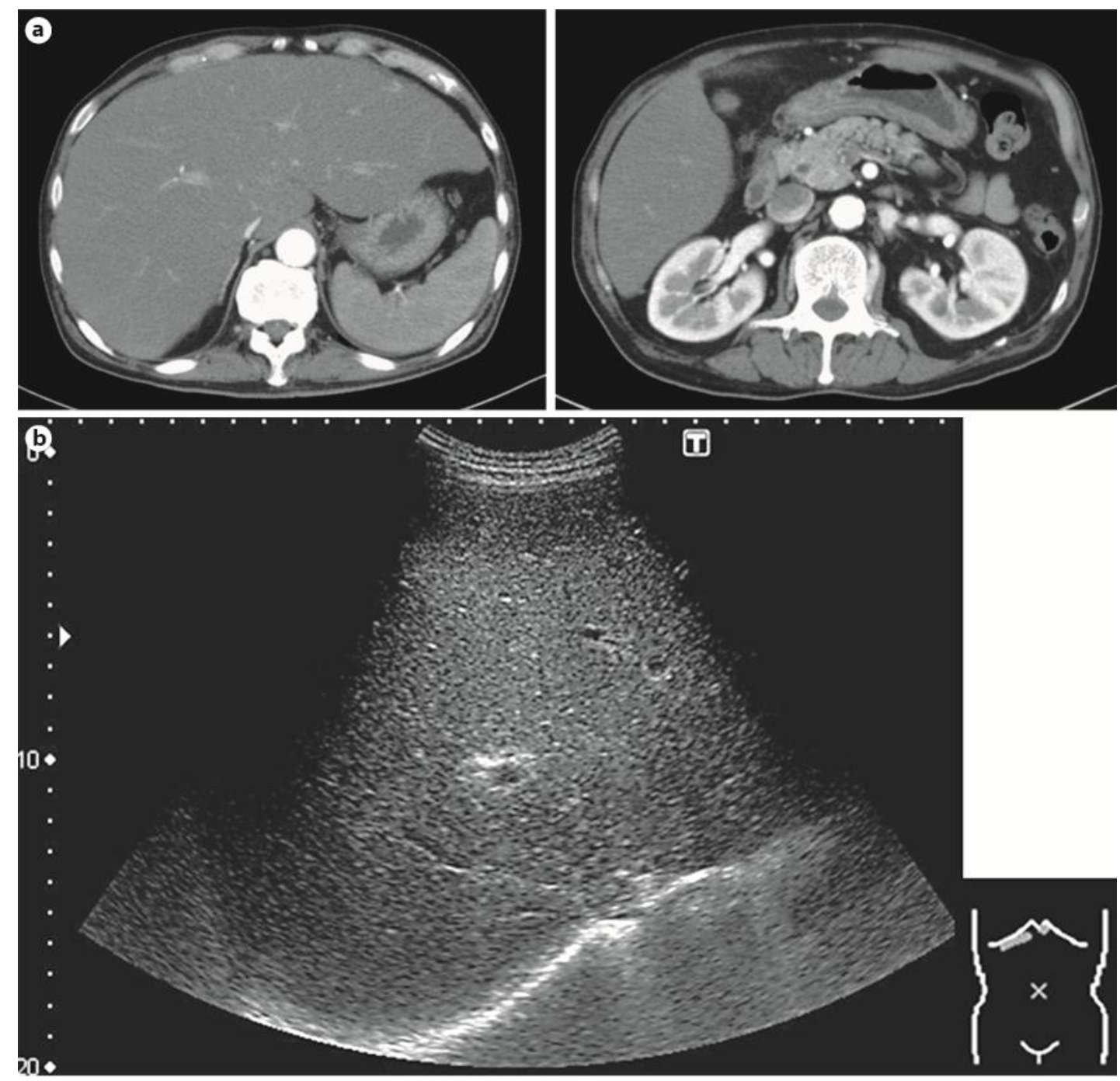

Fig. 2. a Contrast-enhanced CT scans showed only hepatomegaly without any intrahepatic nodular lesions. b An ultrasound sonography examination revealed only diffuse minimal high-echoic nodular shadows.

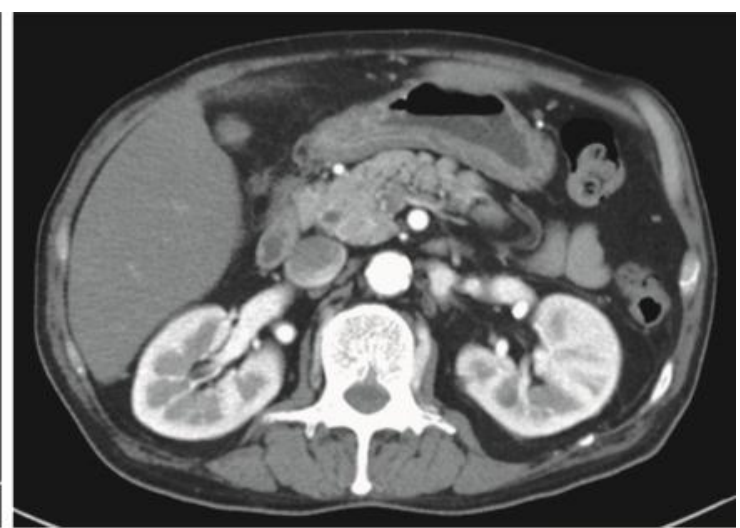




\begin{tabular}{rl|l} 
Case Reports in & \multicolumn{2}{l}{} \\
\cline { 2 - 3 } Gastroenterology & Dos: $10.1159 / 000381140$ & $\begin{array}{l}\text { @ 2015 S. Karger AG, Basel } \\
\text { www.karger.com/crg }\end{array}$ \\
\cline { 2 - 3 } & &
\end{tabular}

Mishima et al.: Diffuse Liver Metastasis of Small-Cell Lung Cancer Presenting as Acute Liver Failure and Diagnosed by Transjugular Liver Biopsy
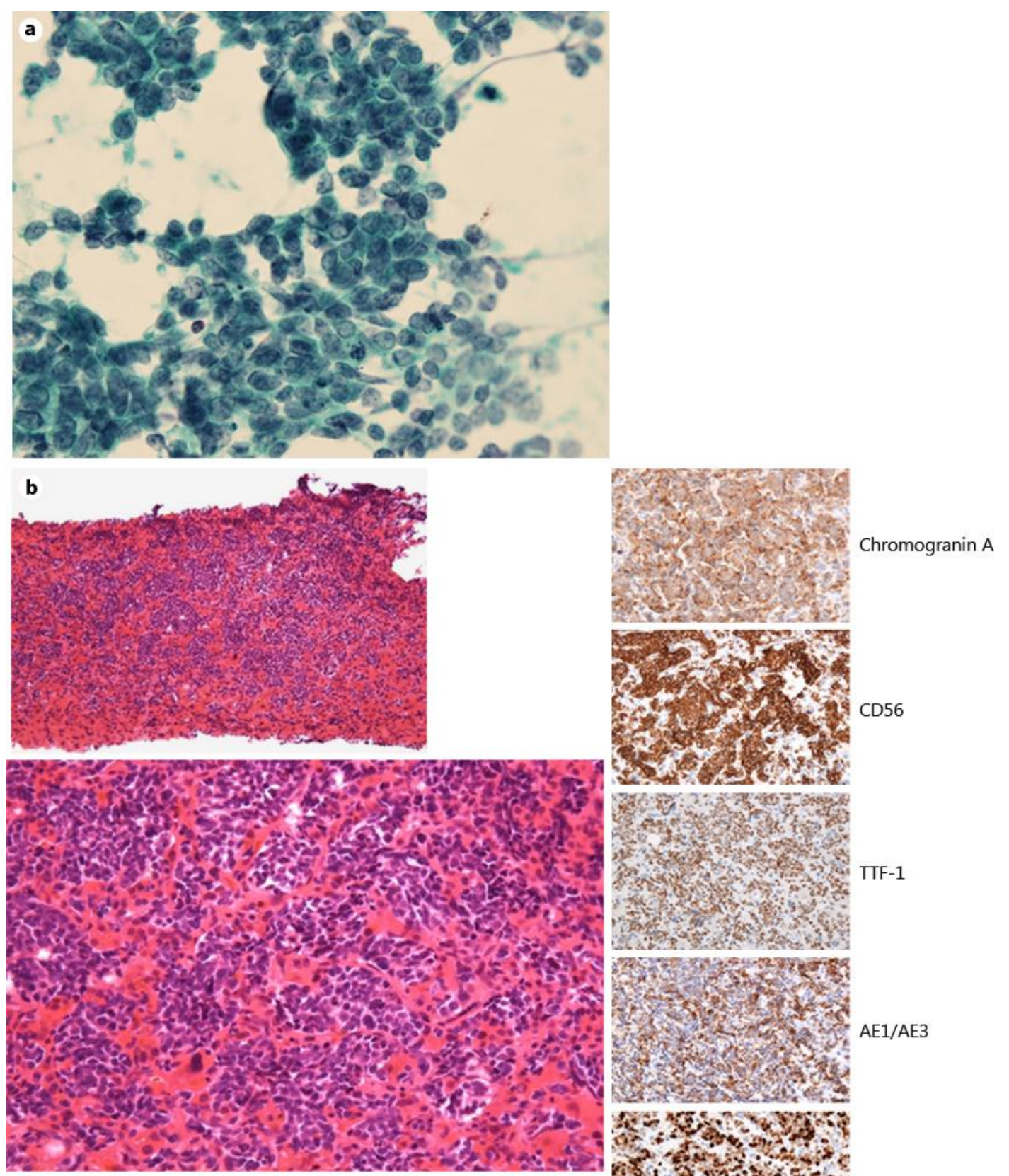

$H \& E$
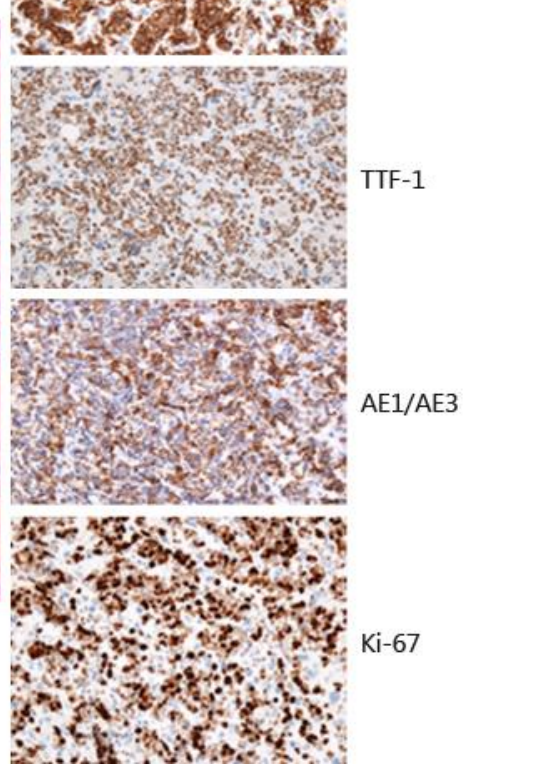

Fig. 3. a Cytology from a mediastinal lymph node by transbronchial needle aspiration revealed SCLC $(\times 400)$. b Histological examination of the liver revealed diffuse liver metastases of SCLC, all of which were positive for chromogranin A, synaptophysin, CD56, TTF-1 and AE1/AE3 and with a Ki-67 index of 80\% (hematoxylin and eosin: ×40, ×400; chromogranin A, CD56, TTF-1, AE1/AE3, Ki-67: ×400). 